Linha D’Água (Online), São Paulo, v. 28, n. 2, p. 137-153, dez 2015

\title{
GÊNEROS ORAIS E ENSINO: ENTRE O DITO E O PRESCRITO
}

\author{
GENDER AND ORAL EDUCATION: BETWEEN SAID AND PRESCRIBED
}

\author{
Linduarte Pereira Rodrigues* \\ Universidade Estadual da Paraíba, Campina Grande, PB, Brasil \\ Maria Aparecida Calado de Oliveira Dantas** \\ Universidade Estadual da Paraíba, Monteiro, PB, Brasil
}

Resumo: Considerando as discussões entre especialistas e outros profissionais preocupados em (re) significar as práticas pedagógicas nas aulas de língua materna, o presente trabalho enfatiza a necessidade de uma revisão e um melhor encaminhamento do fazer docente. Nesse sentido, propõe analisar os pressupostos dos Parâmetros Curriculares Nacionais de Língua Portuguesa (BRASIL, 1998), quanto ao tratamento da oralidade nas práticas de sala de aula, e observar o que, de fato, se efetiva no livro didático de português. Fundamenta-se em teorias linguísticas contemporâneas que alertam para a importância do trabalho com gêneros textuais na sala de aula de língua materna (MARCUSCHI, 2003; MATÊNCIO, 2001; SCHNEUWLY \& DOLZ, 2004), ressaltando as ações docentes frente aos gêneros orais em prol da aprendizagem e do aperfeiçoamento da língua na escola. 0 trabalho evidencia a necessidade de conhecer os pressupostos dos documentos oficiais que regulamentam o ensino de língua portuguesa para que se promova uma avaliação cuidadosa na escolha do livro didático de português, visando à promocãa de situações linguísticas em sala de aula que contemplem o trabalho com gêneros orais. Diante disso, busca participar ativamente do debate sobre a modalidade oral da língua que se constitui objeto de ensino de língua materna na educação básica.

Palavras-chave: oralidade; ensino de língua materna; livro didáfico; documentos oficiais.

\begin{abstract}
Considering the discussions between experts and other concerned professionals in (re) define the pedagogical practices in mother tongue classes, this work emphasizes the need for a review and a better routing to teaching. In this sense, it aims to analyze the assumptions of the National Curricular Parameters for Portuguese Language (BRASIL, 1998), regarding the treatment of orality in classroom practices and observe what, in fact, be effective in the Textbook of Portuguese. It is based on contemporary linguistic theories that call attention to the importance of working with genres in the classioom mother tongue (MARCUSCHI, 2003; MATENCIO, 2001; SCHNEUWLY \& DOLZ, 2004), highlighting the actions teachers face the oral genres for the sake of learning and perfecting the language in school. The paper stresses the need to meet the assumptions of the official documents governing the Portuguese language teaching for to promote a careful assessment in selecting the textbook Portuguese, aimed at the promotion of language situations in the classroom that include working with oral genres. Therefore, actively seeks to participate in the debate on the oral form of the language that is the mother tongue of teaching object in Basic Education.
\end{abstract}

Keywords: Orality; Mother Tongue Teaching; Textbook; Official Documents.

* Professor Doutor, da Universidade Estadual da Paraíba - UEPB, Campina Grande, Brasil; linduarte.rodrigues@bol.com.br

** Professora da Universidade Estadual da Paraíba - UEPB, Monteiro, Brasil; ap.calado@hotmail.com 
Linha D’Água (Online), São Paulo, v. 28, n. 2, p. 137-153, dez 2015

\section{Introdução}

O homem é, essencialmente, ser interativo e se desenvolve pelas relações que estabelece com seus interlocutores mediante a linguagem. Assim sendo, a linguagem funciona como elemento indispensável para a constituição dos sujeitos, uma vez que todas as ações que desenvolvem em sua cotidianidade, nos mais diferentes contextos sociais, efetivam-se por meio da linguagem oral e/ou escrita.

Dessa perspectiva, pode-se afirmar, considerando a ótica bakhtiniana (1995), que a linguagem é, ao mesmo tempo, individual e coletiva, uma vez que, a partir dela, o homem se utiliza da palavra dita para construir seu discurso com relação ao outro. Para Bakhtin/Voloshinov (1995, p. 113),

Toda palavra serve de expressão a um em relação ao outro. Através da palavra, defino-me em relação ao outro, isto é, em última análise, em relação à coletividade. A palavra é uma espécie de ponte lançada entre mim e os outros. Se ela se apoia sobre mim numa extremidade, na outra apoia-se sobre o meu interlocutor.

Para o autor, a linguagem é essencialmente "interação verbal": relações que se efetivam a partir de situações dialógicas e sociais dos sujeitos, as quais funcionam como fios condutores entre os anseios individuais e coletivos. Tais relações permitem o estabelecimento entre os sujeitos mediante a construção de uma teia comunicativa que se efetiva por meio da palavra.

É fato que as interações verbais permitem ao homem se adequar aos diferentes contextos sociais, na medida em que os corpora orais e/ou escritos são arquitetados. Dessa perspectiva, o objeto essencial do ensino na escola deve ser a condição humana, desenvolvendo conhecimentos, capacidades e potencialidades para o exercício consciente e crítico da cidadania. A escola precisa dar primazia às práticas pedagógicas em que o conhecimento técnico-científico, de saberes prontos e acabados, cede lugar ao conhecimento de caráter epistemológico, que possibilita aos sujeitos envolvidos no processo de ensino e aprendizagem da linguagem desenvolver suas potencialidades a partir das interações que estabelecem com o outro, mediados pela palavra e pelos símbolos em situações reais, nos mais diversificados espaços sociais.

Considerando o exposto, entende-se que o trabalho com os gêneros textuais orais se apresenta como uma importante ferramenta capaz de instrumentalizar os sujeitos com vistas ao desenvolvimento das potencialidades de uso da linguagem oral em diferentes contextos de interação social. Assim, este trabalho se propõe a analisar os pressupostos dos Parâmetros Curriculares Nacionais de língua portuguesa (BRASIL, 1998), documento que norteia o ensino de língua materna nos anos 
finais do ensino fundamental e que apresenta, como um dos objetivos para essa fase, a possibilidade dos sujeitos se posicionarem criticamente pelo diálogo, mediando conflitos e tomando decisões coletivas. Igualmente importante, o estudo analisa quatro coleções de livros didáticos utilizados numa escola pública do município de Pombal - PB, uma vez que se considera relevante a orientação didática presente nesses recursos, geralmente, o único material de que dispõe o professor. A seleção levou em consideração que os livros constam do Guia de livros didáticos do Programa Nacional do Livro Didático (PNLD 2014), material didático- pedagógico que serviu de apoio à escola e ao trabalho do professor de língua materna em sala de aula.

Considerando que o ensino de língua portuguesa tem sido objeto de discussão entre especialistas e outros profissionais preocupados em atribuir um novo sentido às práticas de sala de aula, compreende-se a real necessidade de um redirecionamento e um melhor encaminhamento do fazer docente nas aulas de língua materna, com vistas à inserção de metodologias que valorizem as mais diferentes formas de interação dos sujeitos. Diante disso, nas páginas seguintes, enfatizam-se os usos sociais da língua contemplados por autores da linguística contemporânea, com observação documental e registro de dados obtidos em pesquisa qualitativa sobre a importância da modalidade oral da língua a ser enfatizada pela escola.

\section{Por uma pedagogia do oral nas aulas de língua materna}

É recorrente um ensino marcado pela ênfase à modalidade escrita da língua, relegando à oralidade um lugar de desprestígio social, restrito a tímidas ocorrências de leitura em voz alta ou discussão de textos com fim na produção escrita. Também é comum a ideia, com respaldo em correntes estruturalistas da língua, de que desenvolver a oralidade e possibilitar situações de interação social não é competência da escola, partindo do pressuposto de que essa habilidade é anterior a todas as outras formas de interação, uma vez que se constitui no seio da família, quando o sujeito ainda não tem algumas estruturas de fala definidas/constituídas. Entretanto, essa concepção relega o fato de que a oralidade não pode ser reduzida às situações de fala do cotidiano, representadas pela conversa entre amigos e outros eventos próprios do dia a dia das cidades. Essa concepção não leva em conta o fato de que a oralidade contempla também gêneros formais: seminários, debates, discursos, conferências, entre outras situações que exigem do interlocutor o domínio da estrutura do gênero, obtido a partir do letramento escolar e pela mediação do professor.

Sobre esse aspecto, Dolz \& Schneuwly (2004, p. 125) afirmam que, "embora a linguagem oral esteja bastante presente nas salas de aula, afirma-se frequentemente 
que ela não é ensinada a não ser incidentalmente, durante atividades diversas e pouco controladas". É preciso, pois, que a escola se ocupe de situações que permitam ao aluno vivências realistas, no que diz respeito ao tratamento dos usos da oralidade e da escrita. As práticas sociais vinculadas à fala do aluno e o acesso às diferentes modalidades linguísticas e aos usos que se faz delas devem ser experienciados pelos alunos na escola. Matêncio (2001) defende que, por meio do trabalho desenvolvido pela escola, o aluno tem a possibilidade de refletir sobre os processos de funcionamento da linguagem, relacionando-os ao uso efetivo que ele faz da língua e respaldado em suas concepções de socialização.

Considerando o exposto, Dolz \& Schneuwly (2004) afirmam ainda que é papel da escola ensinar ao aluno se apropriar da linguagem oral, em diferentes eventos interacionais, especialmente nos mais formais. Os teóricos apontam para a importância do trabalho fundamentado nos gêneros textuais, considerando que esses têm relação direta com os diferentes setores da atividade humana, a saber: trabalho, relações interpessoais, entre outras situações que exijam dos sujeitos o domínio de estruturas específicas. Corroboram com essa discussão o disposto nos Parâmetros Curriculares Nacionais, quando das orientações para o trabalho didático com os conteúdos que devem ser priorizados pela escola (BRASIL, 1998, p.67):

Ensinar língua oral deve significar para a escola possibilitar acesso aos usos da linguagem mais formalizados e convencionais, que exijam controle mais consciente e voluntário da enunciação, tendo em vista a importância que o domínio da palavra pública tem no exercício da cidadania.

Ainda sobre o trabalho pautado na inserção dos gêneros textuais, Marcuschi (2003, p. 15) afirma que

O trabalho com gêneros textuais é uma extraordinária oportunidade de se lidar com a língua em seus mais diversos usos autênticos no dia-a-dia. Pois nada do que fizermos linguisticamente estará fora de ser feito em algum gênero. Assim, tudo o que fizermos linguisticamente pode ser tratado em um ou outro gênero.

Nesse sentido, o trabalho com os gêneros textuais possibilita a interação entre o oral e o escrito, considerando que um pode servir de apoio ao outro, respeitando as especificidades de cada situação e de cada estrutura que lhes são peculiares, sem que, para isso, seja necessário supervalorizar a modalidade escrita em detrimento da oralidade. 


\section{A aula de língua materna}

Considerando a complexidade apresentada no ensino de língua portuguesa na escola e os problemas de aprendizagem apontados por indicadores educacionais, compreende-se a necessidade de um redirecionamento da prática e um melhor encaminhamento do fazer docente nas aulas de língua materna. Dessa perspectiva, entende-se que é papel do professor primar por sua formação, no sentido de se atualizar e priorizar o desenvolvimento da competência discursiva dos usuários da língua, concebendo a linguagem como uma forma de interação e o texto, um indicador de sentido completo para essas interações (TRAVAGLIA, 2009). Essa atitude revela uma ampla dimensão em que o funcionamento discursivo dos elementos da língua chega a aportar na própria necessidade comunicativa revelada em seus usos sociais.

Esse redimensionamento só será possível a partir de uma compreensão da linguagem como processo interativo, em que os sentidos são construídos a partir das relações dialógicas estabelecidas com os interlocutores e o meio social no qual os sujeitos estão inseridos. Desse modo, é preciso que o professor tenha definida a concepção de homem como ser sociável que, por esta razão, precisa estabelecer relações com os outros e com o meio social no qual se insere, e que atua mediante o uso da linguagem oral e/ou escrita. Bakhtin (2000) considera que o homem, fora de suas interações sociais, não tem existência alguma, necessita estabelecer relações com os outros para ser reconhecido como um ser histórico e social.

Daí a necessidade de práticas de linguagem enfatizadas a partir do estabelecimento de situações que favoreçam aos sujeitos aprendizes a condição de ampliar seus conhecimentos sobre a língua, compreendendo seu funcionamento e usando-a de forma eficiente. Sobre essa questão, Kleiman (1992, p.3) propõe a existência das práticas de letramento, oriundas da intimidade dos falantes com os usos, funções e organização da escrita, que irão refletir na oralidade desses sujeitos, em que seriam aplicadas "as estratégias discursivas do falante para se referir a objetos e eventos não diretamente acessíveis através dos sentidos e para organizar a sua fala”.

Ainda sobre esse aspecto, os Parâmetros Curriculares Nacionais de língua portuguesa (BRASIL, 1998, p.22) destacam que

O objetivo de ensino e, portanto, de aprendizagem é o conhecimento linguístico e discursivo com o qual o sujeito opera ao participar das práticas sociais mediadas pela linguagem. Organizar situações de aprendizado, nessa perspectiva, supõe planejar situações de interação nas quais esses conhecimentos sejam construídos e/ou tematizados; organizar atividades que procurem na sala de aula situações de outros espaços que não o escolar; [...] saber que a escola é um espaço de interação social 
onde práticas sociais de linguagem acontecem e se circunstanciam, assumindo características bastante específicas em função de sua funcionalidade: o ensino.

Desse modo, o ensino de língua precisa desenvolver ações com vistas a formar, preparar, socializar a cultura e prover mecanismos que viabilizem a execução de atividades democráticas de acesso aos bens culturais e procedimentos de ação, reflexão e compreensão linguística de cada sujeito implicado no processo de ensino e aprendizagem. À luz dessa perspectiva, é pertinente ressaltar que a língua não se esgota na compreensão de sua estrutura, mas remete à exterioridade e, assim, "não deve ser tomada como um sistema fechado e imutável, mas como um processo dinâmico de interação, em que interlocutores atuam discursivamente sobre o outro" (PARAÍBA, 2006, p. 22).

Esse paradigma supõe que o professor seja preparado para as mudanças propostas e que as compreenda, crítica e teoricamente. Entretanto, em uma revisão na literatura sobre o desenvolvimento de projetos de pesquisa calcados na prática de ensino de língua materna, constatamos que, seja pela ausência do conteúdo na formação inicial, seja pela qualidade dos cursos de formação continuada e dos materiais usados para tal fim, ainda não se tem efetivada, em sala de aula, uma metodologia de ensino na perspectiva aludida anteriormente, em que se fundamenta o trabalho com os gêneros textuais com vistas ao processo interacional da linguagem. Ainda se mantém viva uma metodologia pautada numa visão estruturalista da língua, com a primazia da "construção" de formas fixas, prontas e definidas.

Sobre esse aspecto, considerando o interesse no trabalho com os gêneros orais em sala de aula, discute-se, a seguir, o espaço ocupado pela modalidade oral na escola que, apesar de se constituir como uma prática muito mais frequente na vida das pessoas, ainda não é contemplada de modo a atender a importância que possui no ato interacional e na consequente constituição dos sujeitos.

\section{O lugar da oralidade na escola}

Muito se discute acerca das práticas pedagógicas nas aulas de língua materna. Estudos revelam uma quase impotência do profissional de ensino em atribuir eficácia ao que se propõe o ensino de língua. É consenso, na escola e nos documentos oficiais, a exemplo dos Parâmetros Curriculares Nacionais, que as ações propostas precisam desenvolver, no aluno, competências linguísticas que o tornem um sujeito socialmente capaz de atuar frente aos eventos diversos de sua cotidianidade. Entretanto, não é difícil perceber a ênfase dada ao trabalho com a escrita em detrimento da oralidade, desprezando o fato de que 


\begin{abstract}
A língua, seja na sua modalidade falada ou escrita, reflete, em boa medida, a organização da sociedade. Isso porque a própria língua mantém complexas relações com as representações e as formações sociais. Não se trata de um espelhamento, mas de uma funcionalidade em geral mais visível na fala (MARCUSCHI, 2005, p. 35).
\end{abstract}

Neste sentido, pode-se dizer que a fala se apresenta como um elemento com fins interativos: gera significados e compartilha saberes entre os sujeitos de um mesmo contexto social e/ou de diferentes esferas comunicativas/interativas.

Assim, desenvolver um trabalho tomando a fala como fator de aprendizagem, a partir da interação com o outro, representa mais do que analisar um conjunto de sons articulados; representa negociar valores e diferentes modos de interpretar situações propostas, considerando que a fala se constitui importante aporte interacional do qual emanam as demais possibilidades de interação com outros sujeitos e o meio social.

Sobre esse aspecto, Antunes (2003) chama a atenção para o fato de que, para possibilitar o desenvolvimento da capacidade de expressão oral dos sujeitos, é preciso ter consciência da importância dessa prática enquanto caráter interacional que se dá entre, pelo menos, dois interlocutores, em torno de um sentido específico e uma intenção determinada, o que permite que a fala deixe de ser um mecanismo meramente espontaneísta, descuidada, e passe a assumir um caráter convencional, de acordo com as situações propostas e os eventos de interação estabelecidos.

Sobre esse aspecto, os Parâmetros Curriculares Nacionais (BRASIL, 1998, p.67) estabelecem que

Ensinar língua oral deve significar para a escola possibilitar acessos a usos da linguagem mais formalizados e convencionais, que exijam controle mais consciente e voluntário da enunciação, tendo em vista a importância que o domínio da palavra pública tem no exercício da cidadania.

A partir dessas orientações e considerando a fala elemento preponderante na constituição dos sujeitos e no estabelecimento de competências que o permitam conhecer, reconhecer e fazer usos dos diferentes gêneros orais nas diferentes situações de sua cotidianidade, isto é, um contexto de uso muito mais real do que o escolar, não se pode relegar a segundo plano o trabalho com a oralidade: "o estudo da oralidade merece ocorrer paralelamente ao da escrita, em razão do continuum e não de um fenômeno com diferenças estanques" (FÁVERO et al, 2012, p. 14, grifo do autor).

Para imprimir, com eficácia, esse tratamento da oralidade no ensino de língua materna, o professor precisa rever e avaliar suas concepções, objetivos, 
procedimentos e resultados do seu fazer docente, considerando a importância de desenvolver um trabalho com o intuito de ampliar a competência comunicativa dos alunos frente aos mais diferentes espaços em que se faça necessário o uso da palavra dita.

Diante do exposto, consideramos pertinente investigar as orientações dos Parâmetros Curriculares Nacionais (BRASIL, 1998) para o ensino da oralidade, bem como as propostas presentes nos livros didáticos de português (LDP), no que diz respeito ao tratamento dessa modalidade, considerando a relevância desses dois suportes no espaço escolar e no planejamento das situações didático-pedagógicas pelo professor.

\subsection{O tratamento da oralidade nos Parâmetros Curriculares Nacionais}

Publicados há pouco mais de uma década (1998), os Parâmetros Curriculares Nacionais têm como objetivo primordial sistematizar referências para o ensino em âmbito nacional, nas diferentes áreas, respeitando as especificidades regionais. Ancorado na Lei de Diretrizes e Bases da Educação Nacional (LDB, Lei 9394/96), o documento tem como elemento mobilizador o desenvolvimento da cidadania, tônica expressa pelo então ministro da educação, na carta de abertura aos professores: "O papel fundamental da educação no desenvolvimento das pessoas e das sociedades amplia-se ainda mais no despertar do novo milênio e aponta para a necessidade de se construir uma escola voltada para a formação de cidadãos" (BRASIL, 1998, p.5).

Considerando o relevante papel das interações sociais e dialógicas no processo de ensino e aprendizagem, os Parâmetros Curriculares Nacionais (BRASIL, 1998) destacam a importância de desenvolver um trabalho pautado no uso da linguagem, nas diferentes instâncias, viabilizando o domínio ativo do discurso nas mais diferentes esferas de comunicação, de modo a ampliar as possibilidades de inserção e participação social do indivíduo no exercício da cidadania.

É com vistas ao trabalho com a língua como objeto de ensino que, no documento em análise, os conteúdos de língua portuguesa estão organizados sob dois enfoques: (1) o uso da língua oral e escrita, em que os gêneros da oralidade se articulam na prática de escuta e na produção de textos orais; (2) a reflexão sobre a língua e a linguagem, que prevê a prática de análise linguística.

Nesse sentido, a escola se configura como um espaço capaz de promover situações didáticas que oportunizem ao aluno 
Utilizar a linguagem na escuta e produção de textos orais e na leitura e produção de textos escritos de modo a atender a múltiplas demandas sociais, responder a diferentes propósitos comunicativos e expressivos, e considerar as diferentes condições de produção do discurso (BRASIL, 1998, p. 32).

Considerando o exposto, a possibilidade de adequação às variadas situações de interação possibilita aos sujeitos condições favoráveis à ampliação de domínio da linguagem e as capacidades de leitura e compreensão nos mais diversos âmbitos sociais, requisito indispensável para uma efetiva participação como sujeito ativo, crítico.

Quanto aos princípios organizadores dos conteúdos de ensino em língua portuguesa, o documento deixa claro que devem ser selecionados conforme a possibilidade de apropriação, por parte do sujeito, que deverá transformá-los "em conhecimento próprio, por meio da ação sobre eles, mediado pela interação com o outro" (BRASIL, 1998, p. 33). Daí a relevância de se proceder a uma abordagem que possibilite ênfase à fala dos sujeitos, com o intuito de refletir e ampliar a competência comunicativa de todos os envolvidos no processo de ensino e aprendizagem, de acordo com os estágios sucessivos de uso da linguagem, "pois é na prática de reflexão sobre a linguagem que pode se dar a construção de instrumentos que permitirão ao sujeito o desenvolvimento da competência discursiva para falar, escutar, ler e escrever nas diversas situações de interação" (BRASIL, 1998, p. 34).

Por outro lado, o documento alerta sobre o equívoco cometido pela escola que relega o espaço da oralidade à discussão de temas abordados em textos que, na maioria das vezes, têm como fim a realização de um exercício escrito. Não significa dizer que essas situações dialogais não sejam importantes, uma vez que aproximam os pares e possibilitam a troca de informações, negociação de sentidos, confronto de opiniões etc. Porém, se o que se busca é o amplo desenvolvimento da competência linguístico-discursiva dos sujeitos no exercício da cidadania, é preciso que sejam dados subsídios ao aluno de modo que ele perceba as diferentes exigências do uso do gênero oral e a necessidade de adequação aos diferentes espaços e diferentes gêneros que exijam o uso da oralidade, de modo formal ou informal.

Nesse sentido, Lima \& Beserra (2012, p. 60) afirmam que "formalidade e informalidade não podem ser dadas como características de uma ou de outra modalidade linguística, mas são, antes, exigências das condições de produção dos diversos gêneros de textos, produzidos sempre em situações específicas”. Diante disso, "cabe à escola ensinar o aluno a utilizar a linguagem do oral no planejamento e realização de apresentações públicas” (BRASIL, 1998, p. 25). Sobre essa questão, destaca-se que, para a efetivação desse princípio, faz-se necessário criar condições e estratégias que favoreçam a transposição de gêneros que ultrapassam os muros 
da escola, procurando dar ênfase à funcionalidade do texto, deixando de priorizar apenas o aspecto estrutural.

Como se vê, o documento que norteia o ensino de língua portuguesa no ensino fundamental é profícuo quanto às orientações sobre a importância de um trabalho pautado no uso dos gêneros textuais orais, com ênfase na fala do aluno; entretanto, ainda não faz parte da cotidianidade da escola e do professor de língua materna a inserção da fala do aluno como gênero oral capaz de promover a autonomia dos sujeitos, apesar do senso comum de que

A fala é uma atividade muito mais central do que a escrita no dia a dia da maioria das pessoas. Contudo, as instituições escolares dão à fala atenção quase inversa à sua centralidade na relação com a escrita. Crucial neste caso é que não se trata de uma contradição, mas de uma postura (MARCUSCHI, 1997, p. 39, grifo do autor).

Dessa perspectiva, pode-se afirmar que os Parâmetros Curriculares Nacionais se apresentam como um suporte capaz de subsidiar as ações empreendidas pela escola e pelo professor de língua materna, entretanto, ainda figuram como "objeto de decoração" nos espaços destinados ao planejamento das ações pedagógicas, quando deveriam funcionar como centro das discussões, no que concerne as possibilidades de efetivação do trabalho com os gêneros orais e consequente desenvolvimento da competência comunicativa dos sujeitos envolvidos no processo de ensino e aprendizagem.

Nesse aspecto, destacamos a necessidade de uma retomada de "postura" no que diz respeito ao tratamento e ao ensino de língua portuguesa, com análise cuidadosa dos documentos oficiais, atentando, principalmente, para a necessidade de empreender um trabalho que atenda às demandas sociais a que os sujeitos envolvidos nesse processo estarão submetidos. Igualmente necessário é compreender a eficácia de um trabalho que dê primazia aos estudos da língua/linguagem como elemento fundamental para a participação social efetiva dos sujeitos.

Entendemos ser importante revisitar as posições assumidas quando da escolha do livro didático, partindo do princípio de que pensar num livro didático que atenda às reais necessidades do sujeito aluno é analisar criticamente as propostas apresentadas em cada material que, geralmente, são carregadas de intenções muito mais comerciais do que pedagógicas, uma vez que sua origem está, historicamente, relacionada ao "poder instituído" (BITENCOURT, 2008). No caso específico do livro didático de língua portuguesa, é preciso entender quais as concepções de linguagem adotadas para, a partir daí, perceber o tratamento 
Linha D'Água (Online), São Paulo, v. 28, n. 2, p. 137-153, dez 2015

dispensado aos diferentes eventos de ação e interação promovidos pela palavra, e as modalidades da língua contempladas, abordagem que será considerada no tópico seguinte.

\subsection{Gêneros orais em livros didáticos de língua porługuesa}

Consideramos, em nosso estudo, a importância de a oralidade ser enfatizada na escola, uma vez que os documentos oficiais (BRASIL, 1998, p.25) que regulamentam o ensino de língua portuguesa no ensino fundamental afirmam que "cabe à escola ensinar o aluno a utilizar a linguagem oral no planejamento de apresentações públicas”. Buscamos verificar se os livros didáticos distribuídos pelo Ministério da Educação (MEC), material mais acessível a alunos e professores das escolas públicas, contemplam situações que possibilitem o desenvolvimento da linguagem em sua modalidade oral, considerando que "há uma estreita relação entre o que e como ensinar: determinados objetivos só podem ser conquistados se os conteúdos tiverem tratamento didático específico" (BRASIL, 1998, p. 65).

Ainda de acordo com o documento:

Ensinar língua oral deve significar para a escola possibilitar acesso a usos da linguagem mais formalizados e convencionais, que exijam controle mais consciente e voluntário da enunciação, tendo em vista a importância que o domínio da palavra pública tem no exercício da cidadania. Ensinar língua oral não significa trabalhar a capacidade de falar em geral. Significa desenvolver o domínio dos gêneros que apoiam a aprendizagem escolar de Língua Portuguesa e de outras áreas (exposição, relatório de experiência, entrevista, debate etc.) e, também, os gêneros da vida pública no sentido mais amplo do termo (debate, teatro, palestra, entrevista etc.) (BRASIL, 1998, p. 67-8).

Sobre esse aspecto, pode-se afirmar que essa concepção possibilita o desenvolvimento de ações capazes de dirimir as dicotomias apresentadas por Marcuschi (2001, p. 27), "dicotomias perigosas", tão fortemente marcadas na escola que acabam por restringir o uso do oral ao campo do improviso e informalidade. 
Linha D’Água (Online), São Paulo, v. 28, n. 2, p. 137-153, dez 2015

\begin{tabular}{ll}
\multicolumn{1}{c}{ FALA } & \multicolumn{1}{c}{ ESCRITA } \\
\hline CONTEXTUALIZADA & DESCONTEXTUALIZADA \\
\hline IMPLÍCITA & EXPLÍCITA \\
\hline CONCRETA & ABSTRATA \\
\hline REDUNDANTE & CONDENSADA \\
\hline NÃO-PLANEJADA & PLANEJADA \\
\hline IMPRECISA & PRECISA \\
\hline FRAGMENTÁRIA & INTEGRADA \\
\hline \multicolumn{2}{c}{ Quadro 1: Dicotomias provenientes da relação fala versus escrita } \\
\multicolumn{2}{c}{ Fonte: Marcuschi $(2001$, p. 27) }
\end{tabular}

Para a oralidade ser tratada como objeto de ensino, é necessário pensar criticamente sobre essas dicotomias, repensando as propostas apresentadas no livro didático (LD) e levadas à sala de aula pelo professor, muitas vezes, sem nenhum questionamento quanto aos aspectos conceituais e metodológicos adotados. Nesse sentido, é importante compreender, inicialmente, a concepção de língua/linguagem adotada pelo livro didático de língua portuguesa (LDP), embora, conforme Marcuschi (2005, p.22), poucos deixam definido o conceito defendido, mas a estrutura apresentada e a ênfase ao código escrito permite entrever que a língua é vista como: "(a) um conjunto de regras gramaticais, (b) um instrumento de comunicação e (c) um meio de transmissão de informação”.

Desse modo, para melhor compreender o tratamento didático atribuído aos gêneros orais, analisamos quatro coleções de livros didáticos de língua portuguesa, destinadas aos anos finais do ensino fundamental $\left(6^{\circ}, 7^{\circ}, 8^{\circ}\right.$ e $9^{\circ}$ Anos $)$, todas aprovadas no PNLD (2008 e 2014), sob a coordenação e pareceres de autores de destaque na Linguística Contemporânea.

A análise foi feita considerando a didatização do gênero oral em cada uma das coleções, buscando mapear que dimensões do ensino são prioridades no material didático ao alcance de alunos e professores da escola campo de pesquisa. Nesse sentido, foi possível estabelecer uma análise comparativa entre as coleções.

Das quatro coleções analisadas, uma foi o livro didático adotado para todas as escolas municipais de ensino fundamental da cidade de Pombal - PB: Jornadas. port, da editora Saraiva. As demais coleções fazem parte do acervo da escola, armazenado na sala dos professores, local onde é realizado o planejamento semanal das atividades pedagógicas, à disposição do professor para eventuais consultas.

As coleções apresentam, basicamente, a mesma estrutura: dividem-se em capítulos e unidades que versam sobre diversos temas que possibilitam ao aluno "ler, escrever, falar e refletir criticamente" (Manual do Professor, página 5). As situações de uso da oralidade estão sempre alinhadas à concepção de oralização do texto 
escrito, uma vez que partem sempre de um texto indicado para leitura e discussão (oral) para, em seguida, proceder às situações de análise escrita.

$\mathrm{O}$ quadro que segue apresenta um panorama da recorrência dos eventos de oralidade nas coleções analisadas:

\begin{tabular}{|c|c|}
\hline COLECÕES & QUANTITATVO DE PROPOSTAS COM ORALIDADE \\
\hline $\begin{array}{l}\text { JORNADAS.PORT } \\
\text { (EDITORA SARAIVA) }\end{array}$ & 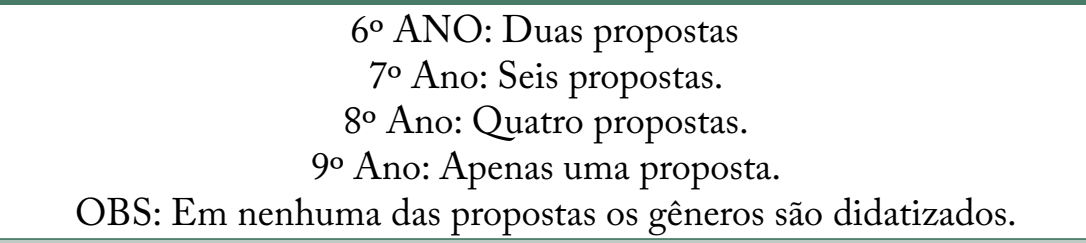 \\
\hline $\begin{array}{c}\text { PORTUGUÊS: } \\
\text { LINGUAGENS } \\
\text { (EDITORA SARAIVA) }\end{array}$ & $\begin{array}{c}\text { 60 ANO: Três propostas. } \\
\text { 7o Ano: Três propostas. } \\
\text { 8o Ano: Uma proposta. } \\
\text { 9o Ano: Apenas uma proposta. } \\
\text { OBS: Em nenhuma das propostas os gêneros são didatizados. }\end{array}$ \\
\hline $\begin{array}{c}\text { PERSPECTIVA: } \\
\text { LÍNGUA PORTUGUESA } \\
\text { (EDITORA DO BRASIL) }\end{array}$ & $\begin{array}{l}\text { Nenhuma proposta específica. A oralidade é entendida como a leitura } \\
\text { em voz alta e/ou breve discussão para iniciar o "trabalho" com o texto. }\end{array}$ \\
\hline $\begin{array}{l}\text { PROJETO ARARIBÁ: } \\
\text { PORTUGUESS (EDITORA } \\
\text { MODERNA) }\end{array}$ & $\begin{array}{l}\text { Nenhuma proposta específica. A oralidade é entendida como a leitura } \\
\text { em voz alta e/ou breve discussão para iniciar o "trabalho" com o texto. }\end{array}$ \\
\hline
\end{tabular}

Quadro 2: Propostas de trabalho com a oralidade por coleção

Fonte: elaborado pela pesquisadora

Embora no Manual do Professor os autores afirmem adotar uma perspectiva de linguagem "que rompe com as correntes que tratam a língua como fenômeno separado do universo social e histórico" (DELMANTO; CARVALHO, 2012, p. 4); "perspectiva de língua como instrumento de comunicação, ação e interação social"(CEREJA; MAGALHÃES, 2012, p. 4), percebe-se, nas obras investigadas, que a ênfase é atribuída ao conceito de língua como mero instrumento de comunicação, uma vez que grande parte dos eventos de linguagem é fundamentado em estruturas que relegam os estudos a estruturas prontas, com exercícios que pouco ou em nada contribuem para o desenvolvimento da competência comunicativa dos sujeitos envolvidos no processo.

De acordo com Marcuschi (2005, p. 22), "as línguas não são apenas um código para comunicação, mas, fundamentalmente, uma atividade interativa (dialógica) de natureza sócio-cognitiva e histórica". Nesse sentido, os LDP em análise pouco abordam a oralidade e, quando o fazem, reservam a esta o lugar do erro ou mero espaço de "discussão" de um texto cujo fim é uma produção escrita. 
São frequentes as propostas que contemplam o desenvolvimento da leitura oralizada, uma vez que se percebe a recorrência da leitura em voz alta ou da discussão coletiva dos textos propostos, no entanto, não há uma preocupação em ensinar o gênero oral, sua arquitetura textual e funcionalidade. Imagina-se apenas que a prática escolar de ler em voz alta contemple o tratamento da modalidade oral. Vêse, assim, que, para todas as situações didáticas do LDP voltadas aos gêneros orais, não é dispensado o mesmo tratamento que se aplica para a modalidade escrita, acreditando que "a aprendizagem da língua oral, por se dar no espaço doméstico, não é tarefa da escola” (BRASIL, 1998, p. 24).

Apesar do tratamento de casos específicos em que a oralidade é enfatizada, não existe, nas situações analisadas, uma preocupação em didatizar o gênero, fazendo com que os sujeitos se apropriem da estrutura e passem a utilizá-lo de modo eficaz, considerando que são inúmeras as situações fora do ambiente escolar em que necessitam dominar as especificidades dos gêneros utilizados em instâncias mais formais e isso só se dará de forma satisfatória se a escola tomar para si a incumbência de promover essa abordagem (BRASIL, 1998). Sobre esse aspecto, Antunes (2007, p. 51) afirma que "não se pode esperar que o falante descubra sozinho um conjunto tão complexo e tão heterogêneo de regras e normas, que, ainda por cima, admitem toda a flexibilidade permitida pela natureza eminentemente funcional da língua”.

Enfatizamos, por essa razão, que as situações didáticas em sala de aula de língua portuguesa precisam contemplar o ensino da modalidade oral da língua, tão presente no cotidiano dos sujeitos. A escola não deve relegar à oralidade o lugar do improviso e de estratégias incompatíveis com a lógica do processo de ensino e aprendizagem, considerando que "a questão não é apenas qual informação deve ser oferecida, mas, principalmente, que tipo de tratamento deve ser dado à informação que se oferece" (BRASIL, 1998, p. 65).

\section{Conclusão}

Considerando as abordagens aqui ressaltadas, muitas são as pesquisas que destacam a importância da oralidade ser enfatizada pela escola na sala de aula. Autores como Geraldi (1997), Marcuschi (2005), Dolz \& Schneuwly (2004), defendem a possibilidade de situações que visem ao desenvolvimento de competências orais nos sujeitos sociais que integram o universo escolar.

Para Geraldi (2002), a linguagem é vista como o lugar da interação humana, pois é por meio dela que o sujeito que fala pratica ações e age sobre o ouvinte. Dolz \& Schneuwly (2004) consideram a oralidade como realidade multiforme, englobando não apenas aspectos fônicos, fonológicos, de entoação, mas também 
explorando lugares mais amplos do oral, como a própria materialidade do texto oral, seu enunciador, seu lugar de enunciação. Do mesmo modo, os Parâmetros Curriculares Nacionais reiteram a importância de a modalidade oral ser enfatizada pela escola, mesmo se tratando de um gênero inerente à condição humana, o que revela ser desconsiderado pelas coleções didáticas analisadas em nossa pesquisa.

A análise realizada permitiu entrever que as atividades contempladas nesses materiais didáticos não atendem à crítica, uma vez que vão de encontro às orientações do documento norteador para o ensino de língua portuguesa nos anos finais do ensino fundamental (BRASIL, 1998), tanto no que se refere à produção quanto à compreensão dos gêneros orais nas diferentes instâncias de uso dessa modalidade da língua.

Segundo Marcuschi (2005, p. 24), o objetivo das atividades com a oralidade na sala de aula deve ser ensinar os alunos a perceberem a riqueza que envolve o uso efetivo da língua como um patrimônio maior do qual não se pode abrir mão, ressaltando o desafio de lidar com as variações linguísticas, considerando o contexto social em que os discursos são produzidos. Por outro lado, percebe-se que "os autores de manuais didáticos, em sua maioria, ainda não sabem onde e como situar o estudo da fala".

Nesse sentido, evidenciamos a necessidade de: i) conhecer os pressupostos dos documentos oficiais que regulamentam o ensino de língua portuguesa para, assim, ii) proceder a uma avaliação mais cuidadosa quando da escolha do livro didático e, principalmente; iii) propor situações de sala de aula que contemplem o trabalho com os gêneros orais, complementando o que propõe o livro didático; além de iv) participar ativamente do debate sobre o fato de que a modalidade oral, embora inerente aos sujeitos sociais como prática "naturalizada", pode e deve se constituir objeto de ensino, uma vez que compõe parte de um sistema linguístico, sendo uma modalidade da língua com regras instituídas por um acordo social.

\section{Referências}

ANTUNES, Irandé. Aula de português: encontro \& interação. São Paulo: Parábola Editorial, 2003.

.Muito além da gramática: por um ensino de línguas sem pedras no caminho. São Paulo: Parábola editorial, 2007.

BAKHTIN, Mikhail. Estética da criação verbal. SP: Martins Fontes, 2000. 
Linha D’Água (Online), São Paulo, v. 28, n. 2, p. 137-153, dez 2015

(VOLOSHINOV). Marxismo e filosofia da linguagem. São Paulo: Hucitec, 1995.

BITTENCOURT, Circe. Livro didático e saber escolar. Belo Horizonte: Autêntica, 2008.

BRASIL. Parâmetros Curriculares Nacionais: terceiro e quarto ciclos do ensino fundamental: língua portuguesa. Brasília, MEC/SEF, 1998.

. Guia de livros didáticos: PNLD 2014: língua portuguesa: ensino fundamental: anos finais. Brasília, MEC/SEF, 2013.

FÁVERO, Leonor Lopes et al (org.). Oralidade e escrita: perspectivas para o ensino de língua materna. 8.ed. São Paulo: Cortez, 2012.

GERALDI, João Wanderley. Portos de passagem. 4.ed. São Paulo: Martins Fontes, 1997.

. O texto na sala de aula. 3. ed. São Paulo: Ática, 2002.

KLEIMAN, Ângela. Texto e leitor: aspectos cognitivos da leitura. 2. ed. Campinas, SP: Pontes, 1992.

LIMA, Ana; BESERRA, Normanda. Sala de aula: espaço também de fala. In: LEAL, Telma Ferraz; GOIS, Siane (org.). A oralidade na escola: a investigação do trabalho docente como foco de reflexão. Belo Horizonte: Autêntica, 2012, p.57-72.

MARCUSCHI, Luiz Antônio. Concepção de lingua falada nos manuais de português de $1^{\circ}$. e $2^{\circ}$. Graus: uma visão crítica. Trabalhos em Linguística Aplicada, Campinas: 1997.

. Da fala para a escrita: atividades de retextualização. 2. ed. SP: Cortez, 2001.

. Gêneros textuais: definição e funcionalidade. In: DIONÍSIO, Angela Paiva et al (org.). Gêneros textuais E̊ Ensino. Rio de Janeiro: Lucerna, 2003, p.19-36.

. Oralidade e ensino de língua: uma questão pouco falada. In: DIONÍSIO, Angela Paiva et al (org.). O livro didático de português: múltiplos olhares. Rio de Janeiro: Lucerna, 2005, p.19-32.

MATÊNCIO, Maria de Lourdes Meirelles. Estudo da lingua falada e aula de lingua materna: uma abordagem processual da interação professor/alunos. Campinas, SP: Mercado das Letras, 2001. 
Linha D'Água (Online), São Paulo, v. 28, n. 2, p. 137-153, dez 2015

PARAÍBA. Secretaria de Educação e Cultura. Referenciais curriculares para o ensino médio da Paraíba: linguagens códigos e suas tecnologias. João Pessoa: A União, 2006.

SCHNEUWLY, Bernard; DOLZ, Joaquim. Gêneros orais e escritos na escola. Tradução e organização de Roxane Rojo e Glaís Sales Cordeiro. Campinas, SP: Mercado de Letras, 2004.

TRAVAGLIA, Luiz. Carlos. Gramática e interação: uma proposta para o ensino de gramática. 14 ed. São Paulo: Cortez, 2009.

Recebido: 30/08/2015

Aprovado: 25/10/2015 